\title{
MENGEMBANGKAN KETERAMPILAN BERPIKIR TINGKAT TINGGI MAHASISWA MELALUI MEDIA SOSIAL
}

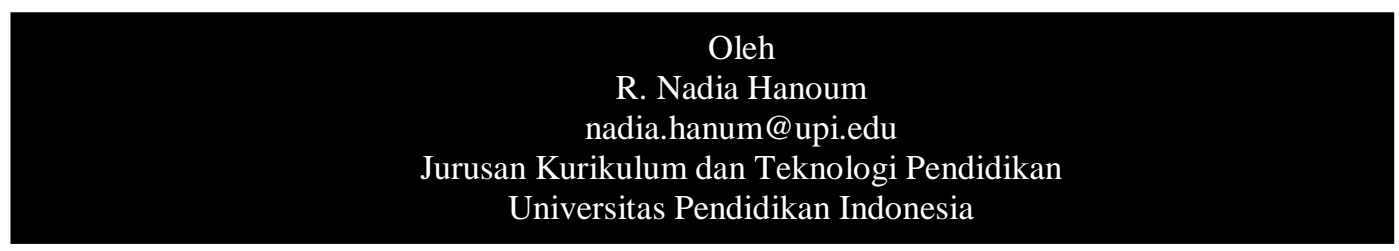

Abstract. Social media allow their users to share, collaborate, and making network more flexibly without having to be in the same place and time. The use of social media in learning gives students more opportunities to interact and exchange information with each other through various activities like discussion, peer correction, and peer evaluation. Viewing from social learning and social constructivism theories, using social media in learning will affect students' behavior and learning outcomes. The learning outcomes explored in this paper is the cognitive domain of analyze, evaluate, and create aspects. These three aspects are considered as higher order thinking skills which should be mastered by college students as it is at university level that quality human resources are expected to be generated.

Keywords: higher order thinking skills, social media, social learning theory

Abstrak. Media sosial memungkinkan para penggunanya untuk berbagi, berkolaborasi, dan berjejaring secara lebih fleksibel tanpa harus berada pada tempat dan waktu yang sama. Penggunaan media sosial dalam pembelajaran memberikan kesempatan yang lebih banyak kepada peserta didik untuk berinteraksi dan bertukar informasi dengan peserta didik lainnya melalui berbagai kegiatan seperti diskusi, mengoreksi informasi yang diberikan oleh teman atau kelompok lain atau memberikan penilaian terhadap kinerja atau penampilan teman sekelas. Jika dilihat dari teori belajar sosial dan teori konstruktivisme sosial, maka penggunaan media sosial dalam pembelajaran akan berdampak pada perilaku dan hasil belajar peserta didik. Hasil belajar yang dieksplor dalam artikel ini adalah domain kognitif aspek menganalisis, mengevaluasi, dan menciptakan. Ketiga aspek ini merupakan keterampilan berpikir tingkat tinggi yang harus dapat dikuasai oleh mahasiswa mengingat pada level pendidikan tinggi lah diharapkan akan dihasilkan SDM yang berkualitas.

Kata Kunci: keterampilan berpikir tingkat tinggi, media sosial, teori belajar sosial

\section{A. PENDAHULUAN}

Di jenjang pendidikan tinggi, peserta didik dituntut untuk tidak hanya sekedar mampu memahami dan menerapkan suatu konsep, tetapi juga mampu menganalisa, mengevaluasi dan menciptakan sesuatu terkait konsep yang telah dipelajari. Jika mengacu pada Bloom's Revised Taxonomy (Krathwohl, 2002), aspek pengetahuan, pemahaman, dan penerapan membutuhkan keterampilan berpikir tingkat rendah hingga sedang, sedangkan aspek analisis, evaluasi, dan kreasi membutuhkan keterampilan berpikir tingkat tinggi. Yang membedakan antara keterampilan berpikir tingkat tinggi dengan keterampilan berpikir tingkat rendah adalah proses kognitif yang terjadi ketika proses pembelajaran berlangsung. Semakin dalam dan kompleks proses kognitif yang 
terjadi, maka akan semakin tinggi pula pemahaman dan tingkat retensi yang dihasilkan.

Untuk mengembangkan keterampilan berpikir tingkat tinggi ini, pendidik dituntut untuk menciptakan suasana belajar yang mendukung dan menggunakan strategi pembelajaran yang dapat memfasilitasi peserta didik dalam melakukan proses berpikir tingkat tinggi. Salah satu cara yang dapat dilakukan adalah dengan menggunakan media pembelajaran yang tepat, yang tidak hanya dapat membantu peserta didik untuk memahami materi pembelajaran tetapi juga membuat peserta didik aktif dalam mengolah pesan atau materi yang harus dikuasai. Seiring dengan perkembangan teknologi, media pembelajaran yang berbasis teknologi juga semakin berkembang dan semakin mudah untuk diadaptasi dan dimanfaatkan untuk tujuan pembelajaran.

Media sosial merupakan salah satu bentuk dari kemajuan teknologi internet yang banyak digunakan dan digemari oleh anak muda. Menurut survey Pew Internet \& American Life Project (2010), 83\% dari pengguna social networking site adalah remaja dan dewasa muda. Media sosial memungkinkan penggunanya untuk berbagi dan berkolaborasi secara fleksibel tanpa terikat waktu dan tempat sehingga penggunaan media sosial dalam kegiatan pembelajaran dapat membuka peluang selebar-lebarnya bagi setiap peserta didik untuk aktif berpartisipasi dalam proses pembelajaran.

\section{B. HASIL DAN PEMBAHASAN}

1. Keterampilan Berpikir Tingkat Tinggi dalam Bloom's Revised Taxonomy

\section{Bloom's}

Taxonomy

memberikan klasifikasi tujuan pembelajaran yang terukur, yang terdiri dari tiga domain yaitu domain afektif, psikomotr, dan kognitif. Dalam lingkup domain kognitif, terdapat enam tingkatan keterampilan berpikir yaitu pengetahuan (knowledge), pemahaman (comprehension), pengaplikasian (application), analisis (analysis), sintesis (synthesis), dan evaluasi (evaluation). Adapun Bloom' revised taxonomy yang dikembangkan oleh Anderson terdiri dari: mengingat (remember), memahami (understand), mengaplikasikan (apply), menganalisis (analyze), mengevaluasi (evaluate) dan menciptakan (create) (Krathwohl, 2002).

a. Mengingat merupakan proses menarik kembali informasi yang relevan dari memori 
Edutech, Tahun 13, Vol.1, No.3, Oktober 2014

jangka panjang. Proses ini melibatkan

aktivitas

mengenali (recognizing) dan mengingat kembali (recalling).

b. Memahami merupakan proses menentukan makna dari informasi yang diterima baik melalui komunikasi lisan, tulisan atau grafis. Proses ini melibatkan aktivitas menafsirkan (interpreting), memberikan contoh

(exemplifying), mengklasifikasikan

(classifying), merangkum (summarizing), mengambil kesimpulan (inferring), membandingkan (comparing), dan menjelaskan (explaining).

c. Mengaplikasikan merupakan proses menyelenggarakan atau menggunakan suatu prosedur dalam situasi tertentu. Proses ini melibatkan aktivitas eksekusi (executing) dan menerapkan (implementing).

d. Menganalisa merupakan proses memecah suatu materi menjadi bagian-bagian dan mendeteksi bagaimana bagian-bagian tersebut terkait satu sama lain dan terkait pada keseluruhan struktur atau tujuan. Proses menganalisa ini melibatkan aktivitas membedakan (differentiating), mengorganisasikan (organizing), dan menghubungkan (attributing).

e. Mengevaluasi merupakan proses membuat penilaian berdasarkan pada kriteria dan standar tertentu. Proses ini melibatkan aktivitas mengecek (checking) dan mengkritisi (critiquing).

f. Menciptakan merupakan proses menggabungkan elemen-elemen untuk membentuk suatu keseluruhan yang baru dan bertalian secara logis atau membuat sebuah produk yang original. Proses ini melibatkan aktivitas menghasilkan (generating), merencanakan (planning), dan memproduksi (producing).

Keenam proses kognitif di atas disusun secara hirarkis dan saling berkaitan satu sama lain. Hirarkis di sini maksudnya pencapaian suatu tingkatan atau tahapan proses tergantung pada pencapian tingkatan sebelumnya. Semakin tinggi hirarki atau 
Edutech, Tahun 13, Vol.1, No.3, Oktober 2014

tingkatan proses berpikir yang terjadi, semakin tinggi pula keterampilan berpikir yang dibutuhkan. Dengan demikian untuk dapat menganalisa, mengevaluasi dan menciptakan dengan baik, maka peserta didik diharuskan untuk dapat mengingat, memahami dan mengaplikasikan dengan baik terlebih dahulu.

2. Aplikasi Keterampilan Berpikir Tingkat Tinggi Melalui Media Sosial

Media sosial merupakan media daring yang menyediakan layanan yang dirancang untuk mempromosikan pengembangan komunitas melalui kegiatan kolaborasi dan berbagi informasi (Arnorld \& Paulus, 2010; Junco, Helbergert, \& Loken, 2011). Media sosial dapat berupa blog, wiki, situs, dan platform jejaring yang memiliki fitur-fitur yang dapat memfasilitasi para penggunanya untuk berekspresi dan berinteraksi dengan sesamanya (Arnorld \& Paulus, 2010).

\begin{tabular}{lr}
\multicolumn{3}{c}{ Keterampilan } & berpikir \\
tingkat tinggi menurut & Bloom's \\
Revised Taxonomy meliputi & menganalisa, \\
keterampilan & menciptakan
\end{tabular}

(King, Goodson \& Rohani, 2009).
Ketiga keterampilan ini dapat dikembangkan lewat penggunaan media sosial yang memfasilitasi penggunanya untuk dapat berkolaborasi dan berbagi dengan pengguna lainnya (Bosman \& Zagenczyk, 2011).

a. Mengembangkan

keterampilan menganalisa lewat media sosial

Media sosial memiliki berbagai fasilitas yang memungkinkan

penggunanya untuk dapat berbagi dan berkolaborasi secara daring. Dengan media sosial seperti Facebook dan Edmodo, pengguna dapat bertemu, berdiskusi dan menganalisa informasi pada satu area kerja yang spesifik atau membangun kelas virtual. Berbeda dengan pertemuan tatap muka, menganalisa informasi secara daring memberikan peserta didik lebih banyak waktu dan kondisi yang bisa jadi lebih kondusif untuk melakukan proses berpikir dan melakukan analisa secara lebih mendalam. Selain itu, hasil analisa yang sudah 
Edutech, Tahun 13, Vol.1, No.3, Oktober 2014

dilakukan dapat terus

diperbaiki kembali hingga

batas waktu yang telah

ditentukan. Hal ini tentu saja

semakin

mengasah

keterampilan menganalisa

dan membuat hasil analisa

semakin tajam.

b. Mengembangkan

keterampilan mengevaluasi

lewat media sosial

Proses mengevaluasi

melibatkan kegiatan

mengecek dan mengkritisi,

dengan mengacu pada

kriteria atau standar tertentu.

Evaluasi yang dilakukan

lewat media sosial seperti

Facebook dan Edmodo

mendorong peserta didik

untuk lebih berhati-hati

dalam memberikan

penilaian karena dalam

prosesnya mendapatkan

waktu yang lebih banyak

dalam membuat

pertimbangan-pertimbangan

sehingga kritikan yang

diberikan lebih berkualitas

dan penilaian yang

dihasilkan pun lebih tepat.

Selain itu, peserta didik akan

lebih percaya diri dalam

memberikan penilaian walaupun penilaian tersebut

dapat dikritisi kembali oleh pengajar atau peserta didik lainnya.

c. Mengembangkan

keterampilan menciptakan lewat media sosial

Saat ini sudah banyak situs-situs tempat berbagi dan menyalurkan kreativitas dalam bentuk produk digital seperti foto digital (Flicker,

Photobucket), suara (Soundcloud) , video (YouTube, Vimeo), dan dokumen (Scribd, Slideshare). Ditampilkannya tugas atau produk hasil kreasi di media sosial dapat memotivasi peserta didik untuk membuat tugas atau menciptakan produk yang lebih berkualitas karena selain dapat dilihat oleh sesama rekan di kelas, tugas atau produk tersebut juga dapat dilihat dan dinikmati oleh semua pengguna media sosial di seluruh dunia.

Dari penjelasan di atas, jelas tergambar bahwa penggunaan media sosial dalam pembelajaran memberikan nilai lebih 
Edutech, Tahun 13, Vol.1, No.3, Oktober 2014

dalam hal keaktifan siswa

untuk berpartisipasi

dibandingkan dengan

pembelajaran yang hanya

mengandalkan tatap muka.

Media sosial memungkinkan

peserta didik untuk lebih

aktif berinteraksi dengan

dosen dan teman sekelas

dan menurut teori belajar

sosial (Bandura dalam Bell-

Gredler, 1986) dan teori

belajar konstruktivisme

sosial (Vygotsky dalam

Jarvis, 2003), interaksi antar

individu dalam proses

pembelajaran berdampak

pada partisipasi aktif siswa

untuk memproses materi

pembelajaran sehingga

berdampak positif pada hasil

belajar.

Lebih jauh lagi menurut

Bandura (dalam Bell-

Gredler, 1986), seseorang

belajar lewat pengamatan

terhadap orang lain dan

menjadikan orang tersebut

sebagai model sehingga

meniru perilaku tersebut

untuk mendapatkan hasil

yang diinginkan. Hal ini

dapat diakomodasi

olehmedia sosial yang memungkinkan peserta

didik berinteraksi dengan

sebanyak mungkin rekannya

sehingga peserta didik

tersebut dapat memilih

model yang sesuai dengan

kondisi psikologis dan intelektualnya. Selain itu

menurut Vygotsky (dalam

Jarvis, 2003), interaksi

sosial merupakan faktor

penting yang dapat memicu

perkembangan kognitif

seseorang. Proses belajar

akan terjadi secara efektif

dan efisien apabila peserta

didik belajar secara

kooperatif dengan peserta

didik lainnya dalam

lingkungan yang

mendukung (student-

centered) dan di bawah

bimbingan seseorang yang

lebih mampu atau dalam hal

ini dosen. Dosen berperan

sebagai fasilitator dalam

interaksi antar dan

kelompok, sedangkan

peserta didik memiliki

otonomi untuk memilah

informasi agar dapat

mendapatkan pemahaman

yang lebih baik tentang 
Edutech, Tahun 13, Vol.1, No.3, Oktober 2014

materi pembelajaran (Chen,

B., \& Bryer, T., 2012).

3. Implikasi terhadap Strategi Pembelajaran

Pembelajaran merupakan suatu aktivitas yang bersifat individual setiap peserta didik memiliki gaya belajar dan motivasi yang berbeda satudengan yang lain. Hal tersebut mempengaruhi seberapa jauh peserta didik dapat sukses dalam belajar. Namun demikian, peran guru juga sangat penting, terutama terkait atmosfir pembelajaran yang diciptakan serta strategi pembelajaran yang digunakan. Strategi pembelajaran yang sangat ideal untuk menumbuhkembangkan

keterampilan berpikir tingkat tinggi adalah stategi yang bertitik tolak pada siswa (studentcentered). Pembelajaran yang berpusat pada peserta didik memungkinkan peserta didik untuk mengekspresikan gagasannya secara terbuka, dan mengembangkan keterampilan berpikir. Dengan kata lain, peserta didik akan lebih aktif dalam kegiatan pembelajaran seperti diskusi, tanya jawab, dan kerja kelompok yang menuntut adanya interaksi dan kerjasama.
Dengan demikian, terkait penggunaan media sosial dalam pembelajaran, penting sekali bagi dosen untuk menggunakan strategi pembelajaran yang tepat mengingat penggunaan media sosial tidak hanya terbatas di dalam kelas tetapi juga berlangsung di luar kelas. Dosen harus memberikan instruksi yang tepat dan jelas agar mahasiswa dapat mengasah keterampilan berpikir tingkat tinggi yang meliputi menganalisa, mengevaluasi dan menciptakan. Strategi pembelajaran yang membuat mahasiswa pasif di kelas tidak akan mampu mengembangkan keterampilan berpikir tingkat tinggi mahasiswa. Keterampilan berpikir tingkat tinggi hanya dapat dikembangkan jika siswa diberi kesempatan untuk secara aktif merekayasa dan mensintesis informasi sedemikian rupa sehingga dapat melengkapi dan memperluas pemahaman yang sudah ada (Knapp \& Glenn, 1996). Tidak lupa pula bahwa keterampilan tingkat tinggi hanya dapat dikembangkan jika keterampilan berpikir tingkat rendahnya sudah berkembang dengan baik. 
Edutech, Tahun 13, Vol.1, No.3, Oktober 2014

\section{SIMPULAN}

Penggunaan media sosial dalam pembelajaran sangat bermanfaat dalam meningkatkan partisipasi aktif peserta didik dalam proses pembelajaran yang pada akhirnya akan berdampak pada hasil belajar. Hal ini dikarenakan media sosial dapat memfasilitasi penggunanya untuk berbagi informasi, berkolaborasi mengerjakan tugas, berdiskusi dengan dosen dan teman sekelas, dan aktivitas lainnya yang seringkali karena keterbatasan waktu tidak bisa diakomodasi di dalam kelas. Terlebih lagi, keterampilan berpikir tingkat tinggi yang meliputi keterampilan menganalisa, mengevaluasi dan menciptakan dapat diasah dan dikembangkan melalui berbagai fasilitas yang diberikan oleh media sosial, seperti Facebook dan YouTube. Kedua media tersebut sudah sangat familiar bagi mahasiswa sehingga dalam penggunaannya mahasiswa tidak akan mengalami banyak kendala teknis sehingga manfaatnya bagi kegiatan pembelajaran dapat dimaksimalkan, yaitu dengan menggunakan strategi pembelajaran yang berpusat pada siswa dan disertai oleh tujuan pembelajaran yang jelas yang disesuaikan dengan tipe media sosial yang digunakan.

\section{DAFTAR PUSTAKA}

Arnold, N., \& Paulus, T. (2010). Using a social networking site for experiential learning: Appropriating, lurking, modeling and community building. Internet and Higher Education, 13, 188-196. Retrieved from

http://gru.edu/qep/documents/articles lusing-social.pdf

Bell-Greadler, Margare E. (1986). Learning and Instruction: Theory into Practice. New York: Macmillan Publishing Company.

Bosman, Lisa \& Zagenczyk, Tom. (2011).

Social Media Tools and Platforms in Learning Environments. New York: Springer.

Chen, B., \& Bryer, T. (2012). Investigating instructional strategies for using social media in formal and informal learning. International Review of Research in Open and Distance Learning, 13(1), 87-104. Retrieved from http://www.irrodl.org/index.php/irro dl/article/view/1027/2073

http://files.eric.ed.gov/fulltext/EJ979 641.pdf

Junco, R. (2012). The relationship between frequency of Facebook use, participation in Facebook activities, and student engagement. Computers \& Education, 58, 162-171. Retrieved from

http://www.ufsa.ufl.edu/uploads/mcd 
Edutech, Tahun 13, Vol.1, No.3, Oktober 2014

a/Facebook_and_Student_Engageme nt.pdf

Jarvis, P., Holford, J., \& Griffin, C. Lenhart, A., Purcell, K., Aaron, S., \& (2003). Theory and Practice of Learning. Virginia: Kogan Page.

King, FJ, Goodson, L.., \& Rohani, F. (2009). Higher Order Thinking Skills. Center for Advancement of Learning and Assessment. Retrieved from

http://www.cala.fsu.edu/files/higher order_thinking_skills.pdf

Knapp, Linda Roehrig \& Glenn, Allen D. (1996). Restructuring Schools with
Technology.Massachusettes: Ally \& Bacon

Zickuhr, K. (2010). Social media \& mobile Internet use among teens and young adults.Pew Internet \& American Life Project. Retrieved from

http://pewinternet.org/Reports/2010/ Social-Mediaand-Young-

Adults.aspx 